\title{
Legitimidade e efetividade em arranjos institucionais de políticas públicas: o Programa Minha Casa Minha Vida
}

\author{
Maria Rita Loureiro \\ Fundação Getulio Vargas / Escola de Administração de Empresas de São Paulo, \\ Departamento de Gestão Pública \\ São Paulo / SP - Brasil \\ Vinicius Macário \\ Fundação Getulio Vargas / Escola de Administração de Empresas de São Paulo, \\ Mestrado em Administração Pública e Governo \\ São Paulo / SP - Brasil \\ Pedro Henrique Guerra \\ Fundação Getulio Vargas / Escola de Administração de Empresas de São Paulo, \\ Mestrado em Administração Pública e Governo \\ São Paulo / SP - Brasil
}

\begin{abstract}
O presente trabalho pergunta se os arranjos institucionais do novo programa habitacional do país, denominado "Minha Casa Minha Vida" (PMCMV), são democráticos e efetivos, ou seja, se incentivam a participação mais ampla de uma pluralidade de atores e se favorecem a implementação e o alcance das metas propostas. A pesquisa empírica permitiu concluir que tais arranjos foram favoráveis ao alcance das metas, mas apresentam déficits democráticos na medida em que atores sociais relevantes na área, como os movimentos populares e os grupos organizados de especialistas em temas urbanos, não têm tido suas demandas contempladas.
\end{abstract}

Palavras-chave: arranjos institucionais; políticas públicas; habitação; Brasil.

Legitimidad y eficacia de las estructuras institucionales de políticas públicas: o Programa Minha Casa Minha Vida

Se indaga aquí si las estructuras institucionales del nuevo programa habitacional del país, llamado de "Minha Casa Minha Vida" (PMCMV), son democráticas y efectivas, o sea, si incentivan la participación más amplia de una pluralidad de actores y si favorecen la implementación y el alcance de las metas

DOI: http://dx.doi.org/10.1590/0034-7612135238

Artigo recebido em 21 maio 2014 e aceito em 10 jun. 2015.

(c) (i)

Uma versão inicial deste trabalho foi distribuída como Texto para Discussão pelo Ipea (TD 1886), que financiou o estudo original. 
propuestas. La encuesta empírica permitió concluir que tales estructuras fueron favorables para el alcance de las metas, pero aun presentan déficits democráticos en la medida que relevantes actores sociales del área, como los movimientos populares y los grupos organizados de especialistas en temas urbanos, no han tenido sus demandas contempladas.

Palabras clave: estructuras institucionales; políticas públicas; habitación; Brasil.

Legitimacy and effectiveness in institutional arrangements in public policies: the housing program My House My Life

This paper questions whether the arrangements of the country's new housing program called "My House My Life" (PMCMV) are democratic and effective. In other words, if they encourage the broader participation of numerous players and if they favor the proposed targets being implemented and achieved. The empirical research showed that such arrangements were indeed favorable in terms of achieving the targets, but that they present democratic shortcomings to the extent that the demands of the relevant social players in the area, as popular movements and organized groups of specialists in urban topics, have not, in fact, been considered.

KEYWORDs: institutional arrangements; public policies; housing; Brazil.

\section{Introdução}

Este trabalho focaliza os arranjos institucionais do novo programa habitacional do país, denominado "Minha Casa Minha Vida" (PMCMV), examinando-os tanto do ponto de vista democrático quanto de sua efetividade para alcançar os objetivos propostos. Ou seja, indaga se tais arranjos incentivam ou não a participação mais ampla de uma pluralidade de atores e se eles favorecem ou não a implementação do programa e o alcance das metas propostas. Por arranjos institucionais entende-se o conjunto de regras, organizações e processos que definem a forma como se coordenam os atores e os interesses em pauta em uma determinada política pública (Gomide e Pires, 2012).

A análise dessa temática se ancora nas formulações da teoria democrática contemporânea, relativas aos impactos dos desenhos institucionais sobre os resultados das políticas públicas. Assim, pode-se mencionar o confronto que Lijphart (1999) realiza, com base em estudo empírico, entre o desempenho das democracias de tipo majoritárias, mais concentradoras do poder no Executivo, com os arranjos institucionais de democracias que ele define de consociativas, nas quais o poder de decisão está mais fragmentado. Contrariando a visão convencional, o autor indica que não há comprovação de que a democracia majoritária seja de qualidade superior, nem tampouco que a rapidez do processo, alcançada nesse modelo majoritário pela redução do número de atores políticos que podem influenciar as decisões, gera necessariamente melhores resultados nas políticas governamentais: "Policies supported by a broad consensus (...) are more likely to be carried out successfully and to remain on course than policies imposed by a 'decisive' government against the wishes of important sectors of society" (Lijphart, 1999:260). 
Também questionando normativa e empiricamente o modelo majoritário de democracia que supõe, a partir de raciocínio meramente dedutivo, a existência de um trade-off necessário entre arranjos mais participativos (portanto, mais representativos) e governabilidade, outros pesquisadores mostram que a estabilidade das políticas públicas (ou seja, o sucesso de sua implementação) vai depender de sua coerência interna (entre seus objetivos), e esta, por sua vez, pode ser aumentada e não reduzida, como se pensa geralmente, em função da existência de estruturas institucionais que exijam amplas negociações e debate entre a pluralidade de atores políticos envolvidos com tais decisões ou políticas.

É o que afirmam Stark e Brustz (1998), estudando arranjos decisórios estabelecidos em três democracias no Leste Europeu após o socialismo. Eles indicam que a capacidade de ação efetiva dos governos pode ser aumentada (e não reduzida) quando o Poder Executivo é menos concentrado, ou seja, é mais constrangido a prestar contas de suas decisões às diversas forças políticas no Parlamento e na sociedade organizada. Tendo que debater e negociar suas propostas com outros atores, os policymakers aumentam a compreensão dos problemas e ampliam a capacidade de obtenção de informações críticas, corrigindo erros de cálculo que, na ausência desse processo, só apareceriam no momento da implementação e, portanto, com menor possibilidade de correção. Isso encoraja, ainda, os formuladores a pensar vários passos à frente nos jogos estratégicos das políticas públicas. Nesse sentido, os processos decisórios inclusivos possibilitam resultados mais eficientes do que aqueles originários de arenas insuladas e de poder concentrado porque aumentam a informação tanto do ponto de vista técnico (soluções alternativas podem emergir) como do ponto de vista da manifestação das diversidades de preferências e soluções políticas sobre o tema em questão.

Com relação ao referencial analítico, serão utilizados aqui quatro tipos de arranjos institucionais que combinam diferentes capacidades estatais, em contextos democráticos, conforme classificação de Gomide e Pires (2012): i) arranjos institucionais legitimadores politicamente, mas debilitadores burocraticamente; ii) arranjos legitimadores e capacitadores; iii) arranjos debilitadores e de baixa legitimação; e $i v$ ) arranjos capacitadores, mas de baixa legitimação.

Cabe esclarecer o que se entende aqui por esses conceitos. São arranjos legitimadores do ponto de vista democrático aqueles que têm arenas decisórias mais consociativas, nos termos de Lijphart. Eles incorporam na formulação e implementação de políticas públicas uma pluralidade de atores estatais e societários, tais como políticos do Executivo e Legislativo, nas diferentes esferas de governo, além de vários segmentos da burocracia (de gestão e controle) e ainda grupos organizados na sociedade civil. Os arranjos com baixa legitimação política são os que se estruturam em arenas decisórias restritas e impermeáveis às demandas do restante do sistema político e da sociedade organizada. O chamado insulamento burocrático seria um típico arranjo de baixa legitimidade política. De modo geral, a visão convencional supõe que o insulamento burocrático seja de alta capacitação, embora estudos mais recentes contrariem tal suposição, tanto na literatura brasileira quanto na estrangeira (Nunes, 1997; Stark e Brustz, 1998; Lijphart, 1999). Já os arranjos debilitadores do ponto de vista burocrático seriam aqueles que não contam com pessoal técnico especializado, não dispõem de informações 
necessárias a sua atuação, tampouco de estruturas organizacionais de coordenação e monitoramento adequadas, ou seja, são aqueles que não favorecem a atuação efetiva dos gestores das políticas públicas. Ao contrário, os arranjos capacitadores seriam os que apresentam tais indicadores.

Em outras palavras, a maior legitimidade democrática de um arranjo institucional depende da maior incorporação de atores políticos relevantes nos diferentes momentos do ciclo da política pública. Já a efetividade do arranjo institucional supõe maior capacidade da burocracia para alcançar os objetivos propostos.

Enfatiza-se que a noção de capacidades estatais envolve não apenas a dimensão técnica e administrativa, mas também a habilidade política dos atores estatais (políticos e burocratas) dentro de um quadro institucional democrático, de articular interesses, negociar com uma gama maior de grupos organizados na sociedade e construir consensos que permitam melhor coordenar a execução e, consequentemente, alcançar melhores resultados.

Nas capacidades políticas são enfatizadas as relações estabelecidas entre a burocracia executora de políticas públicas e outros atores políticos situados institucionalmente tanto no Legislativo e em níveis de governos subnacionais, quanto na sociedade civil organizada (membros de conselhos ou outros colegiados) e ainda com a burocracia da área de controle — Tribunal de Contas da União (TCU), Ministério Público (MP), Controladoria Geral da União (CGU) etc. —, na medida em que a fiscalização acaba também afetando os resultados das políticas.

A hipótese geral que orienta a pesquisa é a seguinte: o PMCMV é política pública com arranjos institucionais de decisão e de implementação legítimos do ponto de vista político e burocraticamente capacitadores, conforme definição anterior. Ou seja, é arranjo legitimador porque leva em conta na definição de seus objetivos as demandas de uma pluralidade de atores políticos. É capacitador porque a burocracia tem demonstrado habilidades em termos políticos e técnico-operacionais, estabelecendo negociação com numerosos atores e desenvolvendo novos instrumentos de gestão e monitoramento. Tal arranjo resultou em eficácia do programa, cuja proxy aqui considerada é o nível de sua execução (cerca de 70\% ou 80\% das metas dentro dos prazos estabelecidos nos cronogramas governamentais).

O PMCMV faz parte do Programa de Aceleração do Crescimento (PAC), lançado em 2007, pelo segundo governo Lula com o objetivo de superar a situação de baixo crescimento econômico do país, por meio do aumento de investimentos públicos em diversas áreas de infraestrutura. O PAC nasceu como desdobramento do Plano Piloto de Investimentos (PPI), proposta negociada com o Fundo Monetário Internacional (FMI), ainda no primeiro governo Lula, para que os gastos em investimentos em infraestrutura fossem debitados do cálculo do superávit primário. Reforçado com a emergência da crise financeira internacional de 2008, o PAC tornou-se programa prioritário do segundo governo Lula e do primeiro governo Dilma orientando-se, como o próprio nome indica, pela urgência e rapidez em apresentar taxas mais elevadas de crescimento. Isso torna seu estudo particularmente interessante para se examinar os impactos dos arranjos decisórios sobre seus resultados, uma vez que se supõe dedutivamente que arenas mais insuladas sejam necessárias para decisões mais rápidas. Assim, se, ao contrário, for constatada a presença de arenas decisórias mais compartilhadas entre um leque 
maior de atores estatais e societários (com arranjos decisórios legitimadores e capacitadores), isso representaria um achado empírico relevante para a configuração de um novo padrão de relação entre Estado e sociedade no Brasil atual e, em particular, um novo padrão de atuação da burocracia encarregada de políticas públicas para o desenvolvimento.

Além desses aspectos que tornam o estudo de programas do PAC um espaço privilegiado de análise de arranjos institucionais, receber o selo PAC por parte de um programa traz ainda importantes implicações políticas: de um lado, significa que ele será incluído em um processo de monitoramento intensivo, coordenado pela Casa Civil e por vários outros colegiados de acompanhamento, como se indicará mais adiante; de outro lado, que ele estará isento de quaisquer contingenciamentos orçamentários.

Com relação à metodologia de pesquisa do estudo de caso do PMCMV procedeu-se, inicialmente, com a revisão da literatura a respeito das políticas de habitação implementadas no Brasil, com destaque para o período do regime militar, quando houve a execução de uma política de grande alcance, via Banco Nacional de Habitação (BNH). Em um segundo momento foram analisados documentos oficiais (leis, decretos, manuais e relatórios) relativos aos principais aspectos do funcionamento do Programa e das instituições envolvidas. Por último, foram realizadas entrevistas semiestruturadas com gestores e ex-gestores ligados à implementação e ao monitoramento do programa em diferentes agências governamentais, principalmente no nível federal de governo, mas também nos níveis subnacionais, com acadêmicos especialistas na área habitacional e, ainda, assessores do Ministério das Cidades. Complementarmente foram utilizadas fontes secundárias — matérias de jornais e textos que exprimiam o posicionamento político das instituições, empresas ou movimentos sociais.

Os dados levantados a partir dessas diferentes fontes de informação foram analisados, cotejando uns com os outros para se obter não só informações mais precisas e consistentes, mas, sobretudo, para se chegar a perspectivas de análise mais plurais a respeito do programa. Em particular, procurou-se confrontar informação de fontes do governo (documentos ou pessoal encarregado do programa) com outras fontes externas.

Como se sabe, o estudo de caso não tem pretensões de generalizar suas afirmações. Sua utilização, segundo Bennet e Elman (2006:468), "possui vantagens quando conceitos, medidas e teorias não estão fortemente validados e quando os objetivos da pesquisa dão mais ênfase na compreensão de como mecanismos causais operam em casos específicos". Ou ainda, nas palavras de Borges (2007:6), frequentemente, a pesquisa qualitativa busca compreender fenômenos cujas causas são de natureza heterogênea, isto é, combinações distintas de causas podem vir a produzir resultados similares, e causas semelhantes operam de maneira diferenciada em contextos distintos.

Todavia, trabalhando com dados quantitativos e qualitativos, com documentos, estatísticas e entrevistas com variados atores, o estudo de caso permite o aprofundamento do tema, inclusive seu acompanhamento no tempo, apreendendo eventuais transformações e diferentes perspectivas. No caso da presente análise do PMCMV, foi possível compará-lo, ainda que brevemente, com arranjos decisórios de políticas habitacionais anteriores, observar algumas mudanças em seu desenho inicial graças ao caráter relativamente mais inclusivo ou consocia- 
tivo dos arranjos institucionais de sua implementação e ainda constatar avaliações divergentes em relação a seu escopo e resultados.

O texto está organizado em quatro partes, além dessa Introdução. Na parte 1 são apresentados, ainda que de forma abreviada, os principais marcos institucionais (regras e organizações) da política habitacional que pautam o PMCMV, bem como as razões e processos que levaram à sua formulação. Na parte 2, indicam-se os atores e interesses aí presentes que se manifestam dentro dos arranjos dessa política tanto no momento de sua elaboração quanto na implementação. Na parte 3 são indicadas as limitações dos arranjos institucionais do programa com relação à participação de grupos organizados na sociedade, o que definimos com déficits de legitimidade democrática. Por fim, são feitas as considerações finais relativas à hipótese de pesquisa, mostrando por que ela foi apenas parcialmente confirmada.

\section{Os arranjos institucionais da área urbana e habitacional no momento do lançamento do PMCMV}

Em 2003, quando se inicia o governo Lula, a política urbana e habitacional no país apresentava grande fragilidade financeira e mesmo institucional, a despeito dos avanços efetuados com a promulgação do Estatuto das Cidades no governo Fernando Henrique Cardoso (FHC). Na verdade, os dois governos de FHC apresentaram uma duplicidade de orientação nessa área de política pública. De um lado, consolidou-se a mudança na orientação da política habitacional com a introdução de mecanismos de mercado. Extinguiu-se o antigo modelo de política habitacional e foi criado um novo, centrado no financiamento ao mutuário final e voltado para a aquisição de imóveis usados (Arretche, 1990). Dois programas se destacam nesse período: o Programa de Arrendamento Habitacional (PAR) operado pela Caixa Econômica Federal (Caixa) e o Programa de Subsídio Habitacional (PSH) para municípios menores. Orientado por visão liberal, este último procurava eliminar intermediários, oferecendo o subsídio diretamente para o subsidiado, por meio de leilão com instituições de financiamento de menor porte. Como um entrevistado apontou, o PSH era muito atrativo politicamente, "porque opera na base dos prefeitos".

De outro, a Emenda Constitucional no 26/2000 deu nova redação ao caput do art. 6o da Constituição Federal de 1988 (CF/1988), alçando o direito à moradia à condição de garantia constitucional, e a promulgação da Lei no 10.257/2001 (Estatuto da Cidade), em cumprimento aos arts.182 e 183 da CF/1988, organizou a política urbana em âmbito federal, oferecendo parte do arcabouço jurídico-institucional com base no qual foram levadas a cabo as políticas habitacionais das duas sucessivas gestões petistas.

Quando se inicia o governo Lula, uma das primeiras medidas nessa área foi a criação do Ministério das Cidades, cedido a Olívio Dutra, ex-governador do Rio Grande do Sul e importante liderança do Partido dos Trabalhadores (PT). Segundo entrevistados, Dutra foi assessorado por uma equipe de técnicos comprometidos com propostas de reforma urbana que visavam "democratizar o direito à cidade", e procurou pôr em prática a integração da 
política habitacional com outras mais amplas e necessárias ao desenvolvimento urbano, tais como saneamento, transportes e planejamento territorial. Essa orientação aparece no texto apresentado na internet na página que divulga a IV Conferência das Cidades: "Combater as desigualdades sociais, transformando as cidades em espaços mais humanizados, ampliando o acesso da população à moradia, ao saneamento e ao transporte. Esta é a missão do Ministério das Cidades, criado pelo presidente Luiz Inácio Lula da Silva em 1 de janeiro de 2003, contemplando uma antiga reivindicação dos movimentos sociais de luta pela reforma urbana" (grifos nossos). Segundo ainda entrevistados, essa equipe de técnicos que foi para o Ministério das Cidades com Dutra havia se formado em torno do Projeto Moradia, movimento organizado dentro do Instituto da Cidadania, ligado ao PT em São Paulo e que, desde o final dos anos 1980, já elaborava "uma resposta aos movimentos sociais" e alternativas ao modelo BNH. Suas propostas envolviam a definição de um prazo de 15 anos como horizonte para que o governo realizasse mudanças profundas na estrutura urbana e na gestão das cidades, garantindo o direito à moradia digna para todo cidadão brasileiro.

Além da criação do Ministério das Cidades, o governo Lula trouxe outras importantes inovações institucionais na área, concretizadas na Lei no 11.124 , de 2005, que cria o Conselho Nacional das Cidades, o Sistema Nacional de Habitação de Interesse Social (SNHIS), incluindo o fundo de financiamento e estabelecendo as bases para a formulação do Plano Nacional de Habitação (PlanHab) que apostava no fortalecimento do planejamento democrático das cidades e, como será visto a seguir, contribuiu de alguma forma no desenho do PMCMV, ao indicar que o déficit habitacional do país se concentrava, sobretudo, na população de renda mais baixa.

O Conselho das Cidades é considerado “a materialização de um importante instrumento de gestão democrática da Política Nacional de Desenvolvimento Urbano (PNDU), então em processo de construção", segundo palavras de seu próprio site na internet. Ele exprime também traço característico do período Lula, que estimulou enormemente a criação e o funcionamento desses colegiados para realizar a interlocução do governo com a sociedade e os demais entes federativos. A mobilização de grupos e movimentos sociais por meio de conferências para debate e formulação de políticas públicas em várias áreas de atuação é traço importante do governo Lula, com impactos significativos para a institucionalização de novas práticas democráticas no país (Pogrebinschi e Santos, 2011). No caso do Conselho das Cidades, seu site na internet afirma ainda que ele permite "viabilizar o debate em torno da política urbana de forma continuada e respeitando a autonomia e as especificidades dos segmentos que o compõem, tais como o setor produtivo, as organizações sociais, as entidades profissionais, acadêmicas e de pesquisa, as entidades sindicais e órgãos governamentais".

Além disso, esse conselho foi, em particular, incentivado pelo próprio ministro Olívio Dutra, como revelou entrevistado do Ministério das Cidades (consultar lista de entrevistados, ao final do texto):

É importante lembrar que o Ministro Olívio bancou a criação do Conselho das Cidades, pari passu com a criação do ministério, optando por fazer uma representação de empresários, movimentos 
sociais, instituições técnicas, de pesquisa e representação de estados e municípios (...) [o que é] completamente diferente dos conselhos de assistência e da educação onde a representação federativa é majoritária. A nossa, por setores, foi uma opção do ministro.

Assim, o PlanHab, elaborado pela Secretaria Nacional de Habitação (SNH) do Ministério das Cidades, foi precedido de ampla consulta à sociedade civil, aos estados e municípios por meio da Conferência Nacional das Cidades. Esse processo ocorreu durante mais de dois anos, mobilizando vários atores na sociedade e no Estado e gerando debates entre grupos de várias regiões do país, com o acompanhamento direto de membros do Conselho Nacional das Cidades e do Conselho Gestor do Fundo Nacional de Habitação de Interesse Social (FNHIS). Como indica documento produzido pela SNH - órgão dentro do Ministério das Cidades que, além de liderar a mobilização da sociedade civil, também representa até hoje a visão do grupo de reforma urbana - o Plano representou a retomada do planejamento do setor habitacional no Brasil ao estabelecer "estratégias de longo prazo para solucionar as necessidades habitacionais do país, presentes e futuras, universalizando o acesso à moradia digna para todo cidadão brasileiro"(Ministério das Cidades, 2010:5).

$\mathrm{Na}$ verdade, a elaboração do PlanHab representou importante momento de capacitação para essa equipe da $\mathrm{SNH}$, porque para sua confecção foram feitos numerosos estudos, diagnósticos e projeções de demanda por habitação para a população de baixa renda, além de análises de temas como a precificação dos produtos, cálculos de necessidade de subsídios etc. Segundo entrevistados, além de definir metas para atender o déficit habitacional para moradias subsidiadas (23 milhões até 2023), as políticas propostas no PlanHab procuraram igualmente superar a tradição de produção estatal de moradia, à maneira do BNH e das Companhias de Habitação Popular (Cohabs), e evitar erros de outras experiências como a do México, no governo Vicente Fox, que criou subsídios para a população de baixa renda sem, entretanto, conectar a construção habitacional a projetos urbanísticos de transporte e serviços de educação e saúde.

No campo do financiamento, o Ministério das Cidades, logo depois de criado, procurou ampliar os recursos disponíveis para a área da habitação, combinando a utilização do FGTS com mecanismos de subsídio. Em 2004 foi aprovada a Lei no 10.391, que estabelece maior segurança jurídica ao financiamento e à produção privada de moradias (isto é, pela lógica de mercado). Em 2005, o CMN também aprovou a resolução que obriga os bancos a investirem em financiamento habitacional uma porcentagem dos recursos captados por meio da poupança. Com a promulgação da Lei no 11.124, que estruturou o SNHIS, criou-se também o FNHIS, aprovado no Congresso em versão modificada à proposta inicial do Ministério e de abrangência mais restrita, já que produziu resistência por parte da área econômica do governo. O FNHIS previa que, a partir da adesão voluntária dos municípios e respeitando alguns princípios mínimos (como a criação de um fundo de habitação municipal, um conselho gestor participativo e a elaboração de um plano), os recursos seriam transferidos diretamente a esses entes federativos, cabendo ao CMN a gestão do fundo. Outra medida importante foi a aprovação da Resolução no 460/2005, pelo Conselho Curador do FGTS, que ampliou os recursos 
disponíveis do fundo para subsídios habitacionais, aumentando o atendimento na faixa de renda mais baixa.

Esse conjunto de medidas resultou na aceleração da produção habitacional. Para se ter melhor ideia desse processo, vale confrontar os resultados dos governos FHC e Lula nessa área: em 2002, o SFH respondeu pela aquisição de apenas 25 mil unidades (de imóveis usados ou construídos), mobilizando um volume de R $\$ 1,4$ bilhão, enquanto em 2008 essas cifras passaram para 280 mil unidades, envolvendo $\mathrm{R} \$ 25$ bilhões (Royer, 2009).

Contextualizando esse conjunto de mudanças institucionais dentro do qual se formará o PMCMV, é importante indicar que o quadro econômico que caracterizou a transição do primeiro para o segundo governo Lula produziu mudanças no aparato de governo, levando a uma ampliação das arenas decisórias das políticas governamentais. A Casa Civil, sob o comando de Dilma Rousseff, além de suas atribuições normais de coordenação institucional das diversas áreas de governo, passou a assumir, com o Ministério da Fazenda e o Ministério do Planejamento, Orçamento e Gestão (MPOG), um papel mais destacado na gestão das políticas econômicas destinadas a enfrentar a crise de 2008, aumentando a participação do Estado na economia e mobilizando recursos públicos para a realização de investimentos (Loureiro, Santos e Gomide, 2011).

Também na área habitacional, a Casa Civil passou a desempenhar papel de destaque. Antes mesmo do lançamento oficial do PMCMV em março de 2009, a então ministra Dilma Rousseff já havia reunido empresários do setor da construção civil, tais como Cyrela, Rossi, MRV, WTorre, Rodobens, ${ }^{1}$ para discutir o tema e já se falava na construção de 1 milhão de casas para a faixa de renda até $10 \mathrm{SMs}$, incluindo a estruturação do fundo garantidor. ${ }^{2}$ A crise financeira de 2008 havia ampliado a capacidade ociosa das empresas do setor da construção civil que, em função do boom imobiliário dos anos anteriores, realizaram grandes investimentos, lançando ações na bolsa e aumentando seus estoques de terrenos. Assim, um novo programa habitacional, a ser priorizado pelo governo, era visto de forma muito favorável pelo empresariado da construção civil que nele encontraria meios de escoar as unidades já em produção e garantir o retorno aos investimentos. Do lado do governo, o setor da construção civil teria importante papel na dinamização da economia e na geração de emprego.

Além de determinantes de ordem econômica, relacionados às medidas de enfrentamento da crise financeira internacional, o surgimento do PMCMV está, também, relacionado a fatores de natureza político-partidária, ligados à substituição do ministro Olívio Dutra, por Márcio Fortes, do Partido Progressista (PP), como resultado de negociações que levaram à reforma ministerial necessária ao reforço da base de apoio do governo no Congresso. Saindo o ministro Dutra, vários assessores técnicos também deixaram o ministério, o que levou ao esvaziamento de parte das políticas em desenvolvimento, em particular o PlanHab,

\footnotetext{
${ }^{1}$ Disponível em: <http://www.cte.com.br/site/ver_noticia.php?id_noticia=516>.

${ }^{2}$ Disponível em: < http://www.piniweb.com.br/construcao/habitacao/walter-torre-antecipou-plano-de-habitacaodo-governo-129663-1.asp $>$.
} 
e reforçou as políticas que contemplavam os interesses de grupos empresariais ligados à construção civil. Entre as medidas que indicam essa inflexão na orientação da política, temos a diminuição dos recursos do FNHIS: esses passaram de R\$ 1 bilhão em 2009 para R\$ 175 milhões em 2010.

Mais forte ainda do ponto de vista de seu significado político, o PMCMV implicou o deslocamento das prioridades antes acordadas à política habitacional (dentro do projeto de reforma urbana) pelo Ministério das Cidades, sob a direção de Olívio Dutra e seus assessores envolvidos com o PlanHab, e a imposição de novas prioridades para a área, determinadas pela necessidade de uma resposta rápida à crise econômica. Na verdade, esse programa representou um importante divisor de águas na área de políticas urbanas e habitacionais. Estas deixaram de ser áreas menos importantes na agenda governamental, tornando-se prioritárias e com isso recebendo volumes extraordinários de recursos jamais vistos anteriormente por seus atores. Segundo dados do Banco Central, o investimento federal incluindo recursos do Sistema Brasileiro de Poupança e Empréstimos e do Fundo de Garantia de Tempo de Serviço, saltou de 7,9 bilhões em 2003 para 101,5 bilhões em 2010 (Brasil, 2014). Já no primeiro governo Dilma, dos $26 \%$ de recursos do Orçamento Geral da União destinados a infraestrutura, mais de $32 \%$ eram voltados para a habitação, o que corresponde ao valor de mais de 387 bilhões. Esse novo cenário trazido pelo PMCMV trouxe impactos importantes sobre os grupos e coalizões formados, como se indicará mais adiante nesse texto.

Internamente ao governo houve mudanças importantes, com destaque para o papel assumido pela Casa Civil que, em sintonia com o Ministério da Fazenda, assumiu a gestão das políticas prioritárias para fazer face à crise e igualmente responder às pressões do empresariado. Tais prioridades puderam ser mais facilmente contempladas com a mudança de comando no Ministério das Cidades. Em outras palavras, o PMCMV implicou que a política habitacional passasse a se configurar como política de cunho predominantemente econômico e não social, ou seja, a necessidade de ativar o mercado passou a se sobrepor ao objetivo de redução do déficit habitacional para trabalhadores de baixa renda, à semelhança do que já havia ocorrido com o programa do $\mathrm{BNH}$, liderado pelo $\mathrm{SFH}$, como a literatura sobre o tema já apontou (Bolafi, 1979; Azevedo e Andrade, 1982; Arretche, 1990). A transformação da política habitacional proposta pela equipe inicial do Ministério das Cidades no formato assumido pelo PMCMV e sua posterior incorporação ao PAC teve duas implicações paradoxais: de um lado, levou à subordinação dos objetivos sociais do programa habitacional aos seus objetivos econômicos e empresariais; por outro, trouxe vantagens significativas, ao torná-lo prioridade na agenda governamental, como revela o depoimento de uma entrevistada no Ministério das Cidades:

Quando se monta a governança do PAC, com a Ministra Dilma e a Miram Belchior na SAM, ali nós nos transformamos efetivamente em prioridade de governo. A política e os programas habitacionais passam a fazer parte do primeiro escalão de governo. A gente que não era nada, não 
sabia se era infraestrutura ou se era política social, um ministério meio híbrido, porque envolve mobilidade, tem saneamento, tem habitação. O urbano é isso tudo, ele é desenvolvimento, mas também enfrentamento da questão social, e para nós isso era fundamental, era um compromisso com a pobreza urbana, era essa a agenda que estava aqui, em parcerias com os movimentos. Além de tudo somos extremamente municipalistas, o ministro Olívio era totalmente comprometido com isso.

A despeito dessa mudança de orientação da política geral do Ministério das Cidades, a SNH continuou sendo o lócus institucional do grupo ligado à reforma urbana e à política de produção de habitação de interesse social, sob o comando de Inês Magalhães que substituiu o antigo secretário, Jorge Hereda, que, por sua vez, assumiu a direção da Caixa Econômica Federal, braço financeiro do PMCMV. Além disso, a SNH foi um espaço institucional do Ministério das Cidades, com capacidade de oferecer ao governo e ao empresariado no momento da crise alternativas (amadurecidas ao longo da elaboração do PlanHab) para dinamizar a atividade econômica. Tal capacidade da burocracia da SNH assentava-se ainda em experiências acumuladas anteriormente por seus técnicos em projetos como o Brasil Habitar - desenvolvido por meio de convênio com o Banco Interamericano de Desenvolvimento (BID) na gestão do Programa de Subsídio à Habitação de Interesse Social (PSH), e mesmo no PAC voltado para ações de urbanização de favelas.

As palavras de um entrevistado são claras mostrando como se deu a capacitação da burocracia da $\mathrm{SNH}$ por meio de experiências anteriores e como ela pôde, assim, oferecer propostas ao núcleo do governo encarregado de enfrentar os impactos da crise de 2008 no Brasil.

A participação dos empresários foi importante, mas não explica a configuração do Programa. Dois fatores (foram) fundamentais para a concepção do PMCMV: a experiência acumulada em programas que já vinham sendo implementados, como o PAR; e o diagnóstico elaborado no PlanHab, tanto em termos do potencial de consumo quanto de apresentar as modelagens de previsão de demanda, precificação e cálculo de subsídios. A opção em criar um programa que não passasse pela rota do FNHIS foi consciente, em função do diagnóstico de que as prefeituras não tinham condições de implementar o programa. Dada a experiência anterior com o PAC (voltado à urbanização de favelas), onde se via a dificuldade das prefeituras executarem os recursos, optou-se por um modelo de contratação direta das empresas.

Mesmo tendo se beneficiado da contribuição decisiva dos técnicos da SNH, o PMCMV emergiu, do ponto de vista institucional, como um programa definido pelo Ministério da Fazenda que estabeleceu as normas de sua regulamentação, a partir de negociações com o empresariado conduzidas pelo secretário executivo, Nelson Barbosa, e executado pela Casa Civil, levando em conta também propostas desenhadas pela $\mathrm{SNH}$. Como atores entrevistados verbalizaram: "O PMCMV é um programa do Ministério da Fazenda, não é um programa do Ministério das Cidades” (Klintowitz, 2015:225). 
Deste modo, o PMCMV se anuncia com o objetivo de construir 1 milhão de moradias destinadas a famílias de baixa renda (cujo limite era, na época, de até $\mathrm{R} \$ 4.650,00$ ) mediante a criação de mecanismos para incentivar a produção ou a aquisição e requalificação de imóveis já existentes. Ou seja, o PMCMV estruturou-se como política de subsídio concedido pelo governo federal, com a criação do Fundo de Arrendamento Residencial (FAR) para o financiamento de unidades habitacionais de famílias com renda de até três SMs. O fundo possibilita que a parcela paga pelo mutuário seja compatível com sua renda e, ao mesmo tempo, garante a rentabilidade do empreendimento realizado por construtoras privadas contratadas pela Caixa, que se responsabiliza pela entrega dos imóveis concluídos e regularizados. Para as famílias com renda até três SMs são utilizados os recursos do FAR, mas há também outras opções para esse público: i) PMCMV-Entidades: financiamento às famílias organizadas por entidades sem fins lucrativos (cooperativas, associações etc.), por meio de recursos do Fundo de Desenvolvimento Social (FDS), as construções podendo ser feitas por administração direta, empreitada global, mutirão assistido ou autoconstrução; ii) Programa Nacional de Habitação Rural (PNHR)/grupo 1: financiamento a agricultores e trabalhadores rurais organizados em entidades sem fins lucrativos; e iii) PMCMV para municípios com população de até 50 mil habitantes: o financiamento é operado por agentes financeiros privados, por meio da oferta pública de recursos.

Os recursos do FAR são distribuídos entre os 27 estados da federação, proporcionalmente à estimativa do déficit habitacional de cada um. A partir da disponibilização desses recursos por parte do governo federal, as agências regionais da Caixa selecionaram os projetos levando em conta a existência de contrapartida pelos governos subnacionais, o menor valor das unidades, a existência prévia de infraestrutura e de equipamentos sociais. Cada empreendimento não pode ultrapassar o total de 500 unidades e deve respeitar critérios arquitetônicos mínimos.

O Fundo Garantidor da Habitação Popular (FGHab) tem o objetivo de garantir o pagamento pelo mutuário da prestação mensal devida aos agentes financeiros, em caso de desemprego e redução temporária da capacidade de pagamento para famílias com renda mensal de até 10 SMs. Esse fundo também cobre o saldo devedor do financiamento, em caso de morte e invalidez permanente, além das despesas de recuperação relativas a danos ao imóvel de mutuários dessa faixa de renda. Tais famílias são financiadas pelo FGTS que só pode comprometer a prestação de até $20 \%$ de sua renda. Recebem carta de crédito da Caixa, com redução dos custos do seguro e acesso ao Fundo Garantidor, procurando diretamente o empreendimento, que, por sua vez, foi financiado pela Caixa, ainda que sem exigências de padrões arquitetônicos mínimos.

O balanço do programa em sua primeira fase, ou seja, do PMCMV1, pode ser considerado bem-sucedido, conforme relatório do TCU, indicando que, até dezembro de 2010, mais de 1 milhão de unidades foram contratadas, em um total de mais de R 53 bilhões financiados e, portanto, alcançando a meta estabelecida, conforme mostra a tabela 1 . 
Tabela 1

Unidades habitacionais contratadas no PMCMV (até 31/12/2010)

\begin{tabular}{|ccccc|}
\hline Faixa (SMs) & $\begin{array}{c}\text { Unidades } \\
\text { contratadas }\end{array}$ & Meta & $\begin{array}{c}\text { \% alcançada } \\
\text { sobre a meta }\end{array}$ & $\begin{array}{c}\text { Valor financiado } \\
\text { (R\$ mil) }\end{array}$ \\
\hline 0-3 & 571.332 & 400.000 & 143 & 23.708 .569 \\
$3-6$ & 287.165 & 400.000 & 72 & 20.309 .665 \\
6-10 & 145.760 & 200.000 & 73 & 9.009 .518 \\
Total & 1.004 .257 & 1.000 .000 & 100 & 53.027 .752 \\
\hline
\end{tabular}

Fonte: TCU (2011).

Na segunda fase do PMCMV, que teve início em 2011, foram concedidos financiamentos subsidiados para 953,6 mil unidades habitacionais. Esse total representa quase a metade de 1,96 milhão de unidades residenciais que tiveram o financiamento contratado por meio do programa habitacional, conforme dados publicados no site do MPOG. Também nessa segunda etapa, o Programa está se expandindo para incorporar trabalhadores rurais. O PNHR tem por objetivo subsidiar a produção ou reforma de imóveis de agricultores familiares e trabalhadores rurais cuja renda familiar anual bruta não ultrapasse $\mathrm{R} \$ 60$ mil. Para melhor avaliação desses números vale confrontá-los com resultados do programa $\mathrm{BNH}$ : a tabela 2 indica que menos de um terço dos financiamentos desse programa contemplou a população de baixa renda.

Tabela 2

Número de financiamentos habitacionais concedidos pelo SFH/BNH (jul. 1964-86)

\begin{tabular}{|cccc|}
\hline & Programas tradicionais (Cohab) & 1.234 .409 & $27 \%$ \\
População de baixa renda & Programas alternativos & 264.397 & $5,9 \%$ \\
& Total de unidades & 1.499 .806 & $33,6 \%$ \\
\hline \multirow{2}{*}{ Mercado econômico } & Cooperativas & 488.659 & $10,9 \%$ \\
& Outros programas & 299.471 & $6,7 \%$ \\
& Total de unidades & 788.130 & $17,6 \%$ \\
\hline Mercado médio & SBPE & 1.898 .975 & $42 \%$ \\
& Outros programas & 280.418 & $6,3 \%$ \\
\hline Total SFH & Total de unidades & 2.179 .393 & $48,8 \%$ \\
\hline
\end{tabular}

Fonte: Azevedo (1988).

\section{Atores e interesses no PMCMV}

Como indicado anteriormente, o PMCMV foi desenhado pela alta burocracia da Casa Civil da Presidência da República com o suporte fundamental do Ministério da Fazenda, a partir de 
negociações com o empresariado, que já havia criado expectativas de investimento na área, com a aquisição de estoques de terreno, abertura de capitais etc. À Casa Civil coube o papel de órgão executor do programa e de coordenador das diferentes agências estatais dele encarregadas, enquanto ao Ministério da Fazenda coube não só a regulamentação das medidas necessárias para o lançamento do programa, mas também a tarefa de importante negociador e articulador das demandas dos grupos empresariais.

Mesmo que o PMCMV tenha "atropelado" as prioridades do projeto da reforma urbana e os investimentos subsidiados para as "habitações de interesse social", o grupo executivo do novo programa habitacional do governo incorporou também algumas demandas trazidas pela equipe de técnicos da SNH do Ministério das Cidades. Conforme alguns entrevistados se expressaram, as negociações permitiram que as demandas desses grupos fossem em parte contempladas, com a introdução da faixa de renda de zero a três SMs (que representa mais de $80 \%$ do déficit habitacional do país) e que não constava da proposta inicial porque não era atrativa ao setor privado orientado pelo lucro. A Caixa também exerceu alguma influência no desenho do programa, estabelecendo critérios técnicos fundamentais no momento da operacionalização e execução do programa. Mas sua atuação será central no momento da implementação, como se verá a seguir.

Cabe enfatizar que a formulação do PMCMV não envolveu o Conselho das Cidades, como ocorrera nos processos decisórios de políticas do Ministério das Cidades, durante a gestão do ministro Olívio Dutra que havia se comprometido a colocar em prática as decisões do conselho, mesmo que esse não tenha sido estabelecido com atribuições deliberativas. Na verdade, tanto o Conselho das Cidades quanto os conselhos municipais criados como requisitos do SNHIS foram esvaziados de suas funções com o lançamento do PMCMV e o predomínio das orientações que o presidiram voltadas para a produção de moradias por meio da iniciativa privada (Klintowitz, 2015). Além disso, continua a autora, o PMCMV também teve como efeito paralelo o desmonte da coalizão estabelecida em 2008 entre empresários e movimentos sociais na formulação e no apoio à PEC Moradia Digna, que estabelecia como regra constitucional 1\% do OGU para a habitação (Klintowitz, 2015:283).

Se o Executivo federal foi o ator central na formulação do PMCMV, é necessário mencionar que também o Congresso dela participou, mesmo que de forma coadjuvante, por meio de propostas que incorporaram os pequenos municípios. O desenho inicial da política formulada pelo Executivo contemplava apenas os municípios de grande e médio porte, onde se concentra o maior déficit habitacional do país. No entanto, durante a tramitação da Medida Provisória (MP) no 459/2009, que criou o programa, houve pressão para que se reservasse parte dos recursos para os municípios menores. Essa articulação foi capitaneada por Henrique Alves (PMDB-RN), líder do partido e relator da matéria, ${ }^{3}$ e envolveu entidades municipalistas que conseguiram garantir uma reserva de até $\mathrm{R} \$ 1$ bilhão como subvenção econômica para

\footnotetext{
${ }^{3}$ Disponível em: <www.camara.leg.br/camaranoticias/noticias/nao-informado/134936-relator-inclui-cidade-com -ate-50-mil-habitantes-em-mp-sobre-moradia.html>.
} 
a extensão do PMCMV a municípios com população de até 50 mil habitantes (art. 19 da Lei no 11.977), o que corresponde a 5.037 municípios, em potencial, ou 90,5\% do total.

Além das entidades municipalistas com poder de influência sobre o PMDB, partido do relator da MP, também contribuiu para a incorporação dos pequenos municípios no programa a mobilização de grupos financeiros que atuam por meio do PSH, voltado à construção de unidades habitacionais em cidades pequenas, como indicou em entrevista um alto funcionário do Ministério das Cidades:

Assim como o PAR (Programa de Arrendamento Habitacional), o PMCMV era metropolitano e para cidades médias. O grupo do PSH também exigiu participar. Os grupos financeiros de segunda linha, como Economisa, organizaram-se no Congresso junto com os prefeitos (...). A cara da nossa Câmara Federal é extremamente pulverizada, e muito influenciada pelos pequenos municípios. [Assim, conseguiram que o programa] atendesse aos municípios abaixo de 50 mil habitantes.

O PMCMV tornou-se bastante atraente para os políticos devido ao grande volume de unidades financiadas e à sua abrangência, atendendo desde cidades pequenas até metrópoles e não só trabalhadores urbanos, mas também rurais. Na verdade, pesquisas eleitorais, efetuadas durante a campanha de 2014, apontam que MCMV era o programa mais lembrado pelos eleitores quando solicitados a mencionar uma política federal (Klintowitz, 2015:231). Diante desse perfil atraente, o governo federal editou a Portaria no 24/2013 que reforça as regras para aplicação da marca do programa, proibindo sua associação a outros e evitando, assim, que governos estaduais e municipais nele "peguem carona".

Também no processo de implementação, a Casa Civil da Presidência da República continuou desempenhando papel de órgão de coordenação centralizada. Como se sabe bem, não há separação nítida, em qualquer política pública, entre a formulação e a implantação, ou seja, parte do desenho da política é especificada, melhor detalhada ou mesmo redefinida no momento de sua execução por várias razões que podem emergir como resposta do governo e da burocracia gestora a demandas sociais não contempladas, às restrições impostas por órgãos de controle e mesmo a críticas de especialistas e de movimentos sociais.

A SNH, do Ministério das Cidades, também foi chamada a participar dos colegiados que monitoram a política e na linha de frente realiza a articulação com a Caixa na execução das operações financeiras do programa. Além de estabelecer diretrizes, regras e condições, a SNH avalia o desempenho do programa, define os limites de renda familiar dos beneficiários, com a Fazenda e o Planejamento.

A Caixa é o órgão público que desempenha papel fundamental na implementação do PMCMV. Além de contratar a operação financeira e acompanhar a execução das obras pelas empresas construtoras, de dar apoio técnico na elaboração de projetos, na prospecção de terrenos, a capilaridade da Caixa no território brasileiro acabou transformando esse órgão em fundamental canal de mediação entre governo federal e os milhares de municípios espalhados pelo país para a execução do programa, e, assim, exercendo o papel inicialmente previsto para 
o MCIDADES. Na verdade, a Caixa disputa com a SNH autoridade e autonomia desde a criação do Ministério das Cidades. Com o lançamento do PAC e do PMCMV como programa prioritário e com o apoio do núcleo estratégico do governo (formado pela Casa Civil, Ministério da Fazenda e pelo MPOG), a Caixa acabou ganhando essa disputa institucional, ampliando seu número de funcionários e sua capacidade operacional (Klintowitz, 2015:146, 231). E, ainda, exercendo também a função de mediador nas negociações com proprietários de terrenos e empresas construtoras. Há depoimentos de construtores apontando a Caixa como o principal incentivador de sua decisão de investir em um determinado município e outros indicando que a Caixa também convenceu determinada empresa a desistir de empreendimentos de casas de veraneio na Baixada Santista e optar pelo investimento no PMCMV na faixa 1, de moradias para trabalhadores de renda mais baixa (Klintowitz, 2015:229).

Com relação aos governos municipais e estaduais, eles e seus respectivos órgãos da administração direta ou indireta participam da implementação do PMCMV por meio de assinatura de termo de adesão com a Caixa. Esse acordo visa assegurar a colaboração daqueles governos em ações que facilitem a execução dos projetos, tais como a seleção das famílias a serem beneficiadas, a indicação de áreas disponíveis ou priorizadas para a implantação do programa, iniciativas de isenção de tributos e ainda a execução do "trabalho técnico social" junto aos beneficiários dos empreendimentos implantados. É só a partir da assinatura desse termo de adesão que a Caixa passa a receber propostas de aquisição de terreno e de produção ou requalificação de empreendimentos para análise.

Quanto às empresas do setor da construção civil, elas participam apresentando propostas e executando os projetos conforme as normas técnicas do programa e guardam os imóveis pelo prazo de 60 dias após sua conclusão e legalização. A figura 1 permite melhor visualizar o fluxo de implementação do PMCMV a partir da alocação do FAR, e a figura 2 abrange a implementação do PNHU.

Figura 1

Fundo de arrendamento residencial

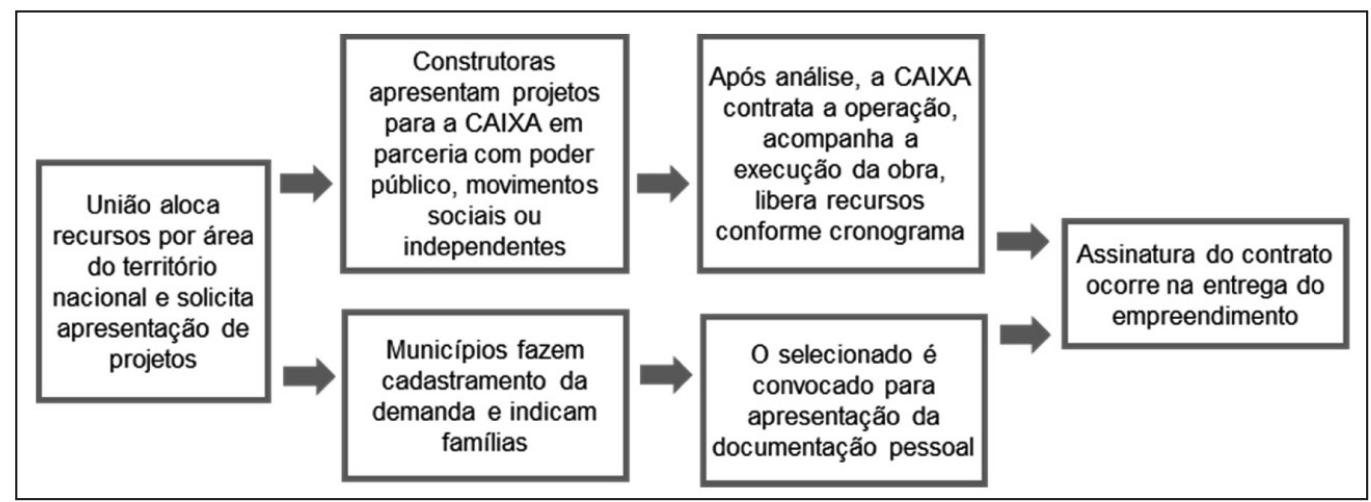

Fonte: Rolnik (2010). 
Figura 2

Fluxo do Programa Nacional de Habitação Urbana (PNHU)

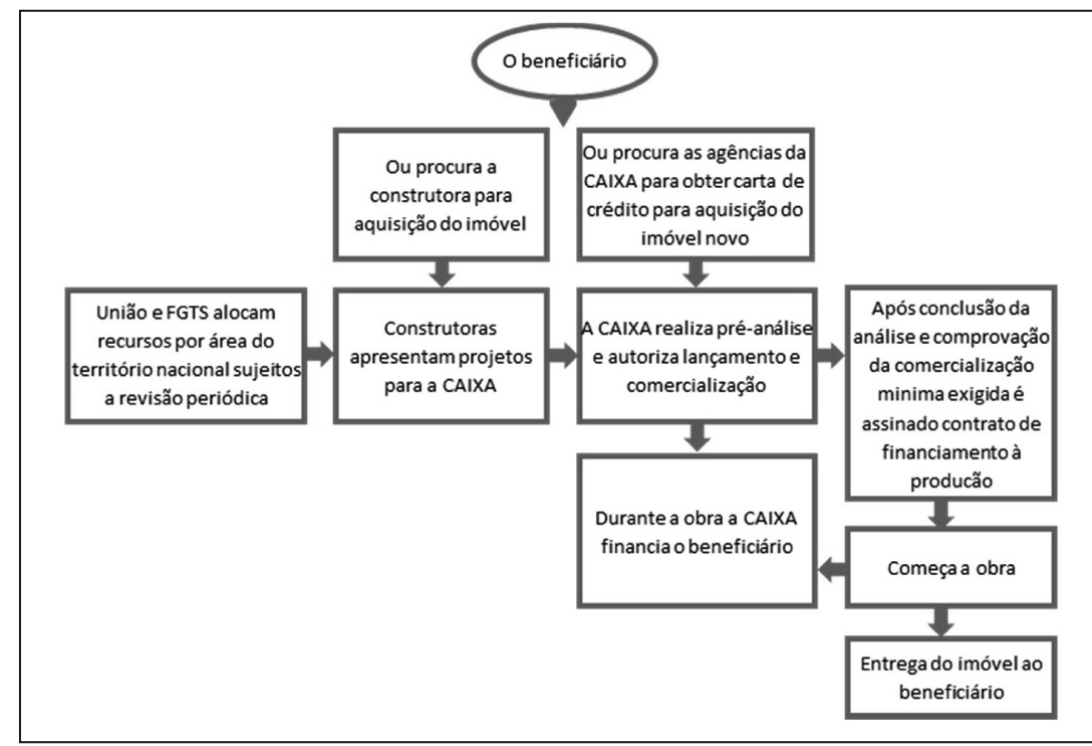

Fonte: Rolnik (2010).

Com relação aos órgãos de controle, eles igualmente compartilharam decisões relativas à implantação do programa. Assim, o TCU, por meio do Acordão no 2.988/2011, fez um conjunto de determinações com vistas a garantir seu melhor cumprimento, tais como o estabelecimento de procedimentos mais rigorosos de verificação da veracidade da renda declarada pelos potenciais beneficiários, previamente à assinatura dos contratos, e a comprovação, pelos municípios, das exigências de hierarquização e seleção da demanda (estabelecidos nos itens 4 e 5 do Anexo à Portaria Ministério das Cidades no 140/2010). As exigências do TCU referemse também à publicidade do processo de seleção dos beneficiários e da contratação de entidades sem fins lucrativos com recursos do FDS. Além disso, o TCU recomendou à CGU avaliar a possibilidade de incluir a verificação do cumprimento dessas exigências nas fiscalizações municipais selecionadas mediante sorteio. Por fim, determinou à Caixa colocar à disposição da SNH todas as informações necessárias ao acompanhamento e à avaliação do PMCMV relativas às operações efetuadas com recursos do FAR.

A incorporação da faixa de zero a três SMs entre os beneficiados do PMCMV trouxe novas exigências necessárias à resolução de problemas operacionais daí decorrentes, tais como preços elevados dos terrenos disponíveis para construção de moradias com valor acessível a essa população e a consequente dificuldade de localização dos empreendimentos em regiões com infraestrutura urbana. Exigiu, também, maior controle por parte dos órgãos públicos para garantir normas mínimas de qualidade arquitetônica das moradias.

Esse conjunto de problemas, que certamente dificultou a realização das metas e dos prazos estipulados no PMCMV, exigiu, por sua vez, inovações em termos dos processos de- 
cisórios, configurando, assim, não só no caso desse programa, mas de vários outros projetos do PAC, novas institucionalidades no processo de execução, com a criação de colegiados para realizar o acompanhamento continuado do programa. Assim, no Decreto no 6.025 de 2007 foram instituídos o Comitê Gestor do PAC (CGPAC), composto pela Casa Civil, Ministério da Fazenda e MPOG, e o Grupo Executivo do PAC (Gepac), composto por secretarias daqueles ministérios, com o objetivo de "consolidar as ações, estabelecer metas e acompanhar os resultados de sua implementação e execução" (art. 4º).

Foram criadas, também, as chamadas "salas de situação", responsáveis pela gestão e tratamento das informações que subsidiam as decisões tomadas no âmbito do Gepac e de CGPAC. Coordenadas pelo MPOG, as salas de situação são compostas por três grupos de atores: $i$ ) servidores designados para acompanhar as ações de um determinado setor; ii) representantes dos três ministérios do CGPAC; iii) servidores de ministérios setoriais (no caso do monitoramento do PMCMV, o Ministério das Cidades). Organizadas por tema (rodovias, aeroportos, saneamento, habitação etc.), as salas de situação realizam o acompanhamento de cronogramas físico e financeiro a fim de assegurar prazos e resultados, gerenciar restrições que possam afetar o desempenho do programa e induzir melhorias nas políticas públicas. ${ }^{4}$

Esse sistema de monitoramento tem desempenhado papel importante na articulação dos órgãos envolvidos, solucionando entraves do programa e, consequentemente, reduzindo o prazo de entrega das unidades. Depoimentos colhidos em entrevistas apontam vários exemplos de questões resolvidas por esses novos canais institucionais de gestão, tais como regularização fundiária, licenciamento ambiental, entre outros. Além disso, pesquisa recente aponta que, por meio desses novos arranjos institucionais, o Executivo federal consegue contornar os efeitos negativos (como perda de controle sobre a política pública) que podem ocorrer com a cessão de cargos na máquina governamental em troca de apoio de partidos da base aliada no Congresso (Macário, 2013). Em suma, ao priorizar o programa na agenda governamental, esse conjunto de mecanismos de monitoramento ajuda a explicar a taxa relativamente bemsucedida de execução do PMCMV.

\section{Os déficits de legitimidade democrática nos arranjos institucionais do PMCMV}

Se considerarmos o arranjo institucional de decisão e de implementação pelo ângulo de sua legitimidade democrática (aqui entendida como maior inclusividade de atores políticos relevantes e de suas demandas, no caso, os grupos populares organizados na sociedade, como movimentos dos sem teto), cabe indicar que o PMCMV apresenta déficits. Se o empresariado da construção civil teve suas reivindicações atendidas no desenho e na implementação do programa, o mesmo não ocorreu com outros segmentos sociais. Com relação aos grupos organizados na sociedade, os segmentos populares não tiveram o mesmo grau de influência

${ }^{4}$ Ver MPOG. Disponível em: <www.planejamento.gov.br/layout/slices/faq.asp?sub=1>. 
dos empresários da construção civil e demais setores imobiliários. Logo após o lançamento do programa, representantes dos movimentos sociais no Conselho Nacional das Cidades reclamaram da ausência de discussão sobre as medidas anunciadas. O conselho gestor do FNHIS se manifestou na mesma direção, afirmando não ter sido ouvido no processo de formulação dessa política (Ministério das Cidades, 2010; Federação de Órgãos para Assistência Social e Educacional -Fase, 2009).

Em vários fóruns e em sites na internet, os movimentos sociais participantes desses colegiados demonstraram preocupação com problemas contidos no desenho do programa, declarando que a construção das unidades precisava estar associada à política urbana que garantisse o acesso a serviços públicos, como saúde, educação transporte, uma vez que eles receavam que fosse repetida a experiência dos conjuntos habitacionais do período BNH. Também urbanistas e profissionais ligados ao Instituto de Arquitetos do Brasil (IAB) afirmam sua pouca articulação com o planejamento urbano e apontam a ausência de mecanismos institucionais e incentivos para financiamento de reformas de moradias subutilizadas. ${ }^{5}$ Pode-se citar, como fato significativo, a reunião realizada em agosto de 2012 em São Paulo, organizada pelo Sindicato de Corretores de Imóveis (Crecisp), com a participação de sindicatos de engenheiros e arquitetos, além de numerosos movimentos populares por moradia, na qual esses grupos criticavam a limitação dos mecanismos institucionais e de incentivos para financiamento de reformas de moradias subutilizadas e demandavam que o PMCMV incorpore a "inclusão e melhoria de imóveis existentes".

Em resposta às preocupações dos movimentos populares e às críticas de especialistas, o governo tem procurando atender, no processo de implementação do programa, questões mais pontuais e também adotar algumas iniciativas para melhorar os padrões técnicos das unidades habitacionais. Por exemplo, diante de afirmações de especialistas de que "as casas eram horríveis", a presidente Dilma Rousseff convidou o autor dessa crítica, o arquiteto João Filgueiras Lima, presidente do Instituto Brasileiro de Tecnologia do Habitat, para desenvolver projetos alternativos de habitação popular. Acolhendo o pedido, o especialista apresentou inovações tecnológicas para a construção de casas em áreas de risco, como os morros na periferia de Salvador, utilizando estruturas metálicas com argamassa armada e montadas manualmente, permitindo, assim, baratear o custo e adaptar-se às necessidades dos moradores.

Ademais, os órgãos encarregados da política também têm procurado modificar o processo de aprovação de grandes empreendimentos na Caixa, que passaram a envolver a alta burocracia do banco e a buscar soluções pactuadas, em casos como o que envolveu a negociação entre o MPOG e a Agência Nacional de Energia Elétrica (Aneel), junto às principais concessionárias de energia elétrica, para garantir que as unidades construídas tivessem infraestrutura pronta no momento de sua entrega aos beneficiários.

Todavia, outras reivindicações não estão sendo atendidas, com destaque para a inclusão ao programa de moradias desocupadas nos centros antigos das grandes cidades. Segundo

\footnotetext{
${ }^{5}$ Ver sites dessas entidades profissionais na internet que trazem várias entrevistas e artigos críticos ao PMCMV.
} 
especialistas, atender a essa demanda específica implica esbarrar em grandes dificuldades de caráter judicial e financeiro, relativas à demora de desapropriar imóveis cujos valores não são pactuados de maneira amigável e, geralmente, atingem cifras muito elevadas. O quadro a seguir sistematiza os principais atores, interesses e seus respectivos pesos políticos no PMCMV.

\section{Quadro 1}

\section{Atores, interesses e influência nos arranjos institucionais do PMCMV}

\begin{tabular}{|c|c|}
\hline Estado: políticos e burocratas & Sociedade civil organizada \\
\hline \multirow{2}{*}{$\begin{array}{l}\text { 1. Presidência da República (Casa Civil) e Ministério da } \\
\text { Fazenda, tendo como principal preocupação ativar } \\
\text { demanda em contexto de crise econômica (núcleo } \\
\text { decisório). }\end{array}$} & $\begin{array}{l}\text { 1. Empresariado da construção civil e do setor imobiliário: } \\
\text { recuperar investimentos prévios e dinamizar mercado } \\
\text { imobiliário (forte influência). }\end{array}$ \\
\hline & 2. Crecisp (influência moderada, com a tentativa frustrada \\
\hline \multirow{2}{*}{$\begin{array}{l}\text { 2. Ministério das Cidades (equipe técnica do SNH, orientada } \\
\text { pelo ideário da reforma urbana): preocupação social } \\
\text { de redução do déficit habitacional, especialmente } \\
\text { para a população de baixa renda (participante do } \\
\text { núcleo decisório, com influência importante por meio } \\
\text { da incorporação de segmentos de baixa renda entre } \\
\text { beneficiários do programa). }\end{array}$} & $\begin{array}{l}\text { de incorporar ao programa a recuperação de moradias } \\
\text { desocupadas). }\end{array}$ \\
\hline & $\begin{array}{l}\text { 3. Representantes de organizações sociais no Conselho } \\
\text { Nacional das Cidades e no Conselho Gestor do FNHIS } \\
\text { (influência pontual, reforçando políticas mais amplas do } \\
\text { desenvolvimento urbano, como saneamento, transportes } \\
\text { etc.). }\end{array}$ \\
\hline $\begin{array}{l}\text { 3. Representantes estatais no Conselho das Cidades e } \\
\text { no Conselho Gestor do FNHIS (influência pontual, } \\
\text { reforçando políticas mais amplas do desenvolvimento } \\
\text { urbano, como saneamento e transportes). }\end{array}$ & $\begin{array}{l}\text { 4. Movimentos sociais (baixa influência, como a tentativa } \\
\text { frustrada de incorporar ao programa a recuperação de } \\
\text { moradias desocupadas). }\end{array}$ \\
\hline $\begin{array}{l}\text { 4. MPOG (influência importante no monitoramento } \\
\text { do programa junto com Casa Civil e SNH). }\end{array}$ & $\begin{array}{l}\text { 5. Entidades municipalistas (influência pontual, com a } \\
\text { incorporação de pequenos municípios ao programa). }\end{array}$ \\
\hline $\begin{array}{l}\text { 5. Congresso Nacional, PMDB } \\
\text { (influência pontual, com a incorporação de pequenos } \\
\text { municípios ao programa). }\end{array}$ & $\begin{array}{l}\text { 6. Grupos financeiros ligados ao Programa de Subsídio à } \\
\text { Habitação (PSH) (influência pontual, com a incorporação } \\
\text { de pequenos municípios ao programa). }\end{array}$ \\
\hline $\begin{array}{l}\text { 6. Caixa, órgão executor das operações financeiras } \\
\text { (influência importante na definição de critérios técnicos } \\
\text { e avaliação de projetos e na mediação entre governo } \\
\text { federal, municípios e construtoras). }\end{array}$ & $\begin{array}{l}\text { 7. Entidades profissionais de arquitetos e engenheiros e } \\
\text { especialistas em áreas habitacionais e questões urbanas } \\
\text { - críticas que levaram à redefinição do desenho do } \\
\text { programa (influência pontual). }\end{array}$ \\
\hline \multicolumn{2}{|l|}{$\begin{array}{l}\text { 7. Prefeituras: foram coparticipantes em ações } \\
\text { complementares na área de infraestrutura urbana. }\end{array}$} \\
\hline \multicolumn{2}{|l|}{ 8. Órgãos de controle: TCU e CGU (influência pontual). } \\
\hline $\begin{array}{l}\text { 9. CGPAC, Gepac e salas de situação (influência importante } \\
\text { na gestão e no monitoramento). }\end{array}$ & \\
\hline
\end{tabular}

Fonte: Elaboração dos autores.

\section{Considerações finais}

Este trabalho procurou analisar os arranjos político-institucionais de decisão do novo programa habitacional brasileiro (PMCMV), examinando-os tanto do ponto de vista de sua legitimi- 
dade democrática quanto de sua efetividade para alcançar os objetivos propostos. A hipótese geral que orientou a pesquisa considerava ser o PMCMV uma política pública com arranjo institucional de decisão politicamente legitimador e burocraticamente capacitador, favorecendo o alcance dos objetivos propostos.

Os dados selecionados para a análise, entretanto, apontaram que essa hipótese só foi confirmada parcialmente, ou seja, do ponto de vista de sua efetividade. As metas estabelecidas foram alcançadas e até mesmo superaram os 100\%, pois o PMCMV foi incorporado ao PAC, tornando-se prioritário na agenda governamental. Como se indicou, isso significou, de um lado, que o programa não seria passível de contingenciamento de recursos orçamentários e, de outro, que ele seria objeto de procedimentos especiais de gestão e monitoramento. Certamente, esses dois fatores contidos no arranjo institucional do PMCMV foram decisivos para o alcance de suas metas. Essa constatação pode representar um achado importante para o entendimento das condições de efetividade de qualquer política pública no país.

Todavia, esse arranjo institucional não se mostrou politicamente legitimador, na medida em que atores sociais relevantes na área, como os movimentos populares e os grupos organizados de especialistas em temas urbanos, não têm tido suas demandas contempladas. O PMCMV está orientado pela lógica empresarial e econômica de curto prazo e não inserido em uma política efetivamente estrutural de planejamento e de reforma urbana que, mesmo exigindo uma perspectiva temporal de longo prazo, é indispensável para melhorar a qualidade de vida nas cidades, como reivindicam os especialistas da área e grupos sociais envolvidos.

Avaliação do PMCMV a partir de um prisma histórico também pode ser feita por meio de um confronto, ainda que breve, com a política habitacional do BNH levada a cabo no país, nas décadas de 1960 e 1970, durante o período militar. Ambas tiveram em comum a participação importante do empresariado da construção civil e dupla orientação, visando não só ao objetivo social de superar o déficit de moradia, mas igualmente ao objetivo econômico de ativar a economia. Os dois programas, também, não conseguiram inserir a política habitacional em um quadro mais amplo de uma reforma urbana com mudanças mais estruturais e de longo prazo.

Todavia, existem diferenças importantes a serem destacadas: o peso extremado da lógica econômica e empresarial sobre a social na política do $\mathrm{BNH}$ certamente tem a ver com o contexto autoritário e repressivo do período e com arranjos institucionais em que as decisões eram tomadas em círculos restritos de atores que gozavam de posição privilegiada junto ao presidente da República ou a algum ministro com mais peso no gabinete ministerial (Vianna,1987; Codato, 1997).

Além disso, os segmentos de baixa renda foram, pela primeira vez, incorporados em programas habitacionais e beneficiados por subsídios governamentais, enquanto no programa do BNH esses subsídios beneficiaram injustamente segmentos de média e alta renda, como farta literatura apontou (Bolafi, 1979; Azevedo, 1988; Arretche, 1990).

No PMCMV, houve a preocupação de atender restrições de ordem legal na construção das moradias, assim como exigências ambientais. Também reivindicações de melhorias técnicas e urbanísticas foram atendidas e, por fim, mas não menos importante, o PMCMV, 
diferentemente dos programas habitacionais anteriores, pautou-se pela orientação de capacitar sistematicamente a burocracia, especialmente dos governos municipais encarregados da infraestrutura urbana.

Em suma, tudo isso está diretamente relacionado ao quadro democrático estabelecido no país, possibilitando o maior comprometimento dos governos com demandas sociais e com a criação de novos aparatos institucionais formados por colegiados de representação mais plural. Em outras palavras, e a despeito das limitações apontadas, a área habitacional e urbana tem apresentado avanços institucionais importantes, com a criação do Ministério das Cidades que mantém uma secretaria (SHN) orientada para a produção de moradias de interesse social, a constituição de fundos de financiamento que ampliaram os recursos para a área, a formação de conselhos que incluem vários segmentos sociais, o aperfeiçoamento de regras de execução e controle de obras etc. Portanto, no exame das práticas políticas que permanecem, não se pode perder de vista também as mudanças sob pena de não termos a compreensão mais completa da realidade.

\section{Referências}

ARRETCHE, Marta. Intervenção do Estado e setor privado: o modelo brasileiro de política habitacional. Espaço e Debates, v. 10, n. 31, p. 21-36, 1990.

ARRETCHE, Marta. Políticas sociais no Brasil: descentralização em um Estado federativo. Revista Brasileira de Ciências Sociais, v. 14, n. 40, p. 111-141, jun. 1999.

ARRETCHE, Marta. Relações federativas nas políticas sociais. Educação e Sociedade, Campinas, v. 23, n. 80, p. 25-48, set. 2002.

AZEVEDO, Sérgio de. Desafios da habitação popular no Brasil: políticas recentes e tendências. In: CARDOSO, Adauto Lúcio (Org.). Habitação social nas metrópoles brasileiras: uma avaliação das políticas habitacionais em Belém, Belo Horizonte, Porto Alegre, Recife, Rio de Janeiro e São Paulo no final do século XX. Porto Alegre: Antac, 2007. p. 12-41.

AZEVEDO, Sérgio de. Vinte e dois anos de política de habitação popular (1964-86): criação, trajetória e extinção do BNH. Rev. Adm. Pública, Rio de Janeiro, v. 22, n. 4, p. 107-119, out./dez. 1988.

AZEVEDO, Sérgio de; ANDRADE, Luis A. Habitação e poder: da fundação da casa popular ao banco nacional de habitação. Rio de Janeiro: Zahar, 1982. p. 55-135.

BENNETT, Andrew; ELMAN, Colin. Qualitative research: recent developments in case study methods. Annual Review of Political Science, n. 9, p. 455-476, 17 fev. 2006.

BOLAFFI, Gabriel. Habitação e urbanismo: o problema e o falso problema. In: MARICATO, Erminia (Org.). A produção capitalista da casa (e da cidade) no Brasil industrial. São Paulo: Alfa-Omega, 1979.

BONDUKI, Nabil. Política habitacional e inclusão social no Brasil: revisão histórica e novas perspectivas no governo Lula. Arquitetura \& Urbanismo. n. 1, 2008. Disponível em: <www.usjt.br/arq. urb/numero_01/artigo_05_180908.pdf>. Acesso em: 10 abr. 2012. 
BORGES, André. Desenvolvendo argumentos teóricos a partir de estudos de caso: o debate recente em torno da pesquisa histórico-comparativa. In: SIMPÓSIO NACIONAL DE HISTÓRIA — ASSOCIAÇÃO NACIONAL DE HISTÓRIA (ANPUH), XXIV, 2007, São Leopoldo.

CASTRO, Ana T. C. B. Reflexos do programa de aceleração do crescimento no Ministério da Integração Nacional. In: CONGRESO INTERNACIONAL DEL CLAD SOBRE LA REFORMA DEL ESTADO Y DE LA ADMINISTRACIÓN PÚBLICA, 13., 2008, Buenos Aires, Argentina. Anais... Buenos Aires: Clad, 2008.

CODATO, Adriano (Org.). Sistema estatal e política econômica no Brasil pós-64. Curitiba: Anpocs; Hucitec; Editora da UFPR, 1997.

EVANS, Peter. O Estado como problema e como solução. Lua Nova, São Paulo, n. 28-29, p. 107-156, abr.1993.

FASE. Federação de Órgãos para Assistência Social e Educacional. Entrevista de Regina Ferreira. Disponível em: <www.fase.org.br/v2/pagina.php?id=3109>. Acesso em: 12 dez. 2012.

GOMIDE, Alexandre; PIRES, Roberto. Capacidades estatais para o desenvolvimento no século XXI. Boletim de Análise Político-Institucional, Brasília, n. 2, p. 25-30, 2012.

KLINTOWITZ, Danielle. Entre a reforma urbana e a reforma imobiliária. A coordenação de interesses na política habitacional brasileira nos anos 2000. Tese (doutorado) — Programa de Pós-Graduação em Administração Pública e Governo, Escola de Administração de Empresas de São Paulo, Fundação Getulio Vargas, São Paulo, 2015.

LIJPHART, Arend. Patterns of democracy: government forms and performance in thirty-six democracies. New Haven: Yale University Press, 1999.

LOUREIRO, Maria Rita; SANTOS, Fabio; GOMIDE, Alexandre. Democracia, arenas decisórias e política fiscal no governo Lula. Revista Brasileira de Ciências Sociais, v. 26, n. 76, p. 63-76, jun. 2011.

MACÁRIO, Vinicius. Coordenação governamental no presidencialismo de coalizão: o Programa de Aceleração do Crescimento e o seu impacto no Ministério dos Transportes. Dissertação (Mestrado) — Fundação Getulio Vargas, São Paulo, 2013.

MINISTÉRIOS DAS CIDADES. Plano Nacional de Habitação. Versão para debates. Brasília: Ministério das Cidades/Secretaria Nacional de Habitação, maio 2010. Disponível em: <www.sst.sc.gov. br/arquivos/id_submenu/230/publiicacao_planhab_capa.pdf>. Acesso em: 25 ago. 2013.

NUNES, Edson. A gramática política do Brasil: clientelismo e insulamento burocrático. Rio de Janeiro: Zahar, 1997.

POGREBINSCHI, Tamy; SANTOS, Fabiano. Participação como representação: o impacto das conferências nacionais de políticas públicas no Congresso Nacional. Dados: Revista de Ciências Sociais, v. 54, n. 3, p. 259-305, 2011.

ROLNIK, Raquel et al. Como produzir moradia bem localizada com recursos do programa minha casa minha vida? Implementando os instrumentos do Estatuto da Cidade. Brasília: Ministério das Cidades, 2010. Disponível em: <www.fau.usp.br/cursos/graduacao/arq_urbanismo/disciplinas/ aup0535/Cartilha_-_Minha_Casa_Minha_Vida.pdf>. Acesso em: 3 mar. 2013. 
ROYER, Luciana. Financeirização da política habitacional: limites e perspectivas. Tese (doutorado) — Faculdade de Arquitetura e Urbanismo, Universidade de São Paulo, São Paulo, 2009.

STARK, David; BRUSTZ, Lazlo. Enabling constraints: fontes institucionais de coerência nas políticas públicas no pós-socialismo. Revista Brasileira de Ciências Sociais, v. 13, n. 36, p. 13-39, fev. 1998.

TCU. Tribunal de Contas da União. Relatório e parecer técnico do governo da República. Brasília: TCU, 2011.

VIANNA, Maria Lucia. A administração do "milagre": o conselho monetário nacional (1964-67). Petrópolis: Vozes, 1987.

Maria Rita Loureiro é professora titular departamento de Gestão Pública da Fundação Getulio Vargas de São Paulo (FGV/SP). E-mail: marita.loureiro@gmail.com.

Vinicius Macário é mestre em administração pública e governo pela Fundação Getulio Vargas de São Paulo (FGV/SP).E-mail: vimacario@hotmail.com.

Pedro Henrique Guerra é mestre em administração pública e governo pela Fundação Getulio Vargas de São Paulo (FGV/SP). E-mail: pedrogiocondoguerra@gmail.com.

\section{Apêndice}

\section{Lista de entrevistados}

v Entrevistada A - Rede Internacional de Ação Comunitária (Interação) e ex-consultor do Ministério das Cidades (entrevista realizada em 17 de janeiro de 2013).

v Entrevistada B - Coordenação Técnica do PlanHab (entrevista realizada em maio de 2012).

v Entrevistada C - Diretoria de Desenvolvimento Institucional e Cooperação Técnica do Ministério das Cidades (entrevista realizada em 16 de janeiro de 2013). Brasília (DF).

v Entrevistada D - Departamento de Produção Habitacional do Ministério das Cidades (entrevista realizada em 1ํo de agosto de 2012). Brasília (DF).

v Entrevistado E - Departamento de Programa de Habitação do PAC. Secretaria do PAC, no Ministério do Planejamento (entrevista realizada em 30 de julho de 2012).

v Entrevistado F - Departamento de Programa de Rodovias e Ferrovias (entrevista realizada em 30 de julho de 2012).

v Entrevistado G - Membro do movimento Pró-Moradia e vereador na Câmara de Vereadores de São Paulo (entrevista realizada em julho de 2012). 